\title{
PRODUÇÃO DE PETRÓLEO E IMPACTOS AMBIENTAIS: ALGUMAS CONSIDERAÇÕES
}

\author{
S. S. S. MARTINS ${ }^{*}$, M. P. SILVA, M. O. AZEVEDO e V. P. SILVA \\ 'Diretoria Acadêmica de Recursos Naturais - Instituto Federal do Rio Grande do Norte \\ silas_sarkiz@hotmail.com*
}

Artigo submetido em junho/2014 e aceito em novembro/2015

DOI: $10.15628 /$ holos.2015.2201

\section{RESUMO}

O petróleo está a cada dia sendo mais explorado e tem sido um recurso energético gerador de divisas para a economia de países e nações, a exemplo do Brasil, mas, também, difusor de impactos ambientais negativos. As etapas que envolvem a produção de petróleo desde a perfuração de poços até o refino, direta ou indiretamente, têm causado alterações ao meio ambiente. O objetivo deste estudo foi o de compreender os principais impactos ambientais gerados pelas etapas de produção de petróleo, considerando estudos de impacto ambiental (EIAs) e seus respectivos relatórios de impacto ambiental (RIMAs). A avaliação dos impactos ambientais se dá através do diagnóstico ambiental da área de influência do empreendimento, o qual é feito para se conhecer os componentes dos meios físico, biológico e socioeconômico da área e, posteriormente, avaliar os efeitos das atividades do empreendimento sobre os mesmos. Pela complexidade da composição química do petróleo, o risco quanto as suas atividades e seu manuseio é, na maioria dos casos, de grande potencial, pois pode haver acidentes, que, por sua vez, podem interferir negativamente no meio ambiente. Ao término do estudo, concluiu-se que a fase de produção de petróleo apresenta diversos aspectos ambientais, os quais geram impactos. Viu-se que os impactos não são apenas de caráter negativo. E, por fim, sugere-se a aplicação de medidas mitigadoras e de um sistema de gestão ambiental eficaz para a minimização e/ou eliminação de tais impactos.

PALAVRAS-CHAVE: Petróleo, Produção, Impacto ambiental.

\section{OIL PRODUCTION AND ENVIRONMENTAL IMPACTS: SOME CONSIDERATIONS}

\section{ABSTRACT}

The petroleum is being each day more explored in Brazil and has been an energy resource generator of currencies to the economy of countries, for example of Brazil, but, also, diffuser of negative environmental impacts. The stages that involve the petroleum's production from well drilling to refining direct or indirectly, has caused environmental changes. The objective of this study was to understand the major environmental impacts caused by petroleum's production stages, considering environmental impacts studies (EISs) and their respective environmental impacts reports (EIRs). Environmental impact assessment is based on diagnosis of project direct influence area, which is done to know the aspects of physical, biological and socioeconomic area and then
\end{abstract}

evaluate the effects of project activities on them. Due to complexity composition of petroleum's chemistry, the risk in relation to its activities and its handling it's, on most of instances, of large potential, because there may be accidents which, in turn, may adversely affect the environment. At the end of this study, we conclude that the production phase of petroleum presents several environmental aspects which generate impacts. However, we have seen that such impacts are not only negative in character. Finally, we suggest the application of mitigation measures and an effective environmental management system to minimize and/or eliminate such impacts.

KEYWORDS: Petroleum, Production, Environmental Impact. 


\section{INTRODUÇÃO}

O petróleo é um combustível fóssil que apresenta muitas utilidades e aplicações, além do uso na indústria automobilística. Ele se caracteriza por ser matéria-prima e/ou constituinte de diversos produtos como plásticos, calçados e cosméticos. Apresenta também grande potencial energético, já que grande parte da produção de energia global é baseada nesse combustível. Entretanto, a utilização do petróleo não apresenta apenas aspectos positivos, visto que ele possui alto potencial de aspectos e impactos ambientais que são resultantes de sua exploração e produção industrial, sendo capaz de causar a morte de animais e plantas, além de comprometer a qualidade do solo, do ar e das águas.

Esse combustível fóssil é um dos principais constituintes da economia do Brasil e do mundo. Ou seja, o petróleo é um recurso energético que é responsável por boa parte das divisas que integram a economia nacional. No contexto atual, ou seja, a partir do século XXI, com a descoberta e a produção do pré-sal a partir de $2008^{1}$, o Brasil passou a apresentar um grande potencial de evolução econômica e aumento do produto interno bruto (PIB) fundamentado na passagem do cargo de produtor autossuficiente para o de produtor exportador.

Este estudo tem o objetivo precípuo de compreender os principais impactos ambientais gerados pelas etapas de exploração e produção de petróleo, tecendo algumas considerações importantes. A pesquisa em tela teve o apoio financeiro do Programa de Formação de Recursos Humanos (PFRH), criado pela Petrobras junto com a Agência Nacional do Petróleo, Gás Natural e Biocombustíveis (ANP), que visa preparar estudantes de ensino técnico, neste particular, para atuar no setor de óleo e gás.

Para a realização deste estudo, optamos por uma metodologia qualitativa de investigação, de caráter bibliográfico e documental, em que foram utilizadas diversas fontes de pesquisas, tais como: livros, artigos, estudos de impacto ambiental (EIA), relatórios de impacto ambiental (RIMA), dentre outras. Uma parcela das fontes foi adquirida por meio da internet, através do site da biblioteca central Zila Mamede, da Universidade Federal do Rio Grande do Norte (UFRN); e do Instituto Brasileiro do Meio Ambiente e dos Recursos Naturais Renováveis (IBAMA), por exemplo. A outra parcela foi adquirida na biblioteca Sebastião Fernandes, do Instituto Federal de Educação, Ciência e Tecnologia do Rio Grande do Norte (IFRN).

Foram realizados fichamentos e resumos de literaturas referentes a petróleo e impactos ambientais, os quais foram importantes para a construção do embasamento teórico necessário para o desenvolvimento deste estudo.

Quanto ao caráter documental, o presente estudo foi realizado através da observação dos impactos ambientais listados nos seguintes estudos de impacto ambiental (EIAs) e relatórios de impacto ambiental (RIMAs): Atividade de perfuração marítima blocos BM-POT-16 e BM-POT-17, Bacia Potiguar (BRASIL, 2010); Desenvolvimento e escoamento da produção de petróleo bloco BM-

\footnotetext{
${ }^{1}$ A produção do pré-sal já é uma realidade brasileira, o que contribui para que se tenha uma posição estratégica frente à grande demanda de energia mundial nos próximos anos. A produção do pré-sal, por exemplo em 2008 , superou 100 milhões de barris de petróleo. Informações da Petrobras dão conta de que são mais de 400 mil barris, nas bacias de Santos e de Campos. Tem-se uma previsão de que em 2018, 52\% da produção total de óleo venha do pré-sal. Vale enfatizar que, em 11 de maio de 2014, um novo recorde já foi batido: foram 470 mil barris por dia (PETROBRAS, 2014).
} 
C-41, Bacia de Campos (BRASIL, 2011); e Desenvolvimento integrado da produção e escoamento na área denominada parque das Baleias e no campo de Catuá (BRASIL, 2007).

Esses estudos e relatórios foram escolhidos por tratarem exclusivamente de algumas etapas constituintes da fase de produção de petróleo. Através deles, pudemos compreender os reais impactos gerados pela indústria petrolífera, em sua fase de produção, alcançando o objetivo do presente estudo.

O presente artigo, além desta parte introdutória, encontra-se estruturado da seguinte maneira: uma segunda seção que se refere aos fundamentos teóricos, onde são apresentados os principais conceitos necessários para a produção do estudo em questão; a terceira seção aborda as histórias do petróleo no mundo e no Brasil, respectivamente; a quarta seção apresenta a influência do petróleo na matriz energética brasileira; a quinta seção trata dos processos de produção de petróleo, nos quais estão inseridos a exploração, a terminação, a produção propriamente dita e o refino; a sexta seção aborda a definição dos principais impactos ambientais; e na sétima seção apresentamos as nossas considerações finais. Além disso, foram arroladas as referências básicas utilizadas pelo estudo.

\section{PRODUÇÃO DE PETRÓLEO E IMPACTOS AMBIENTAIS: BREVES REFERENCIAIS TEÓRICOS}

Este referencial teórico objetiva explicitar os principais conceitos ou termos utilizados como base para a realização deste estudo, o qual compreende um estudo sobre os impactos ambientais provenientes da produção de petróleo. Discutimos teoricamente sobre os conceitos de petróleo e de impacto ambiental fundamentando-nos em alguns autores, buscando os suportes para as reflexões de nossas ideias e, consequentemente, para o embasamento do estudo como todo.

\subsection{PETRÓLEO}

Etimologicamente, a palavra petróleo provém do latim pretoleum, que significa pedra (petrus) e óleo (oleum). A importância do petróleo para sociedade contemporânea é, de fato, notável. A ideia de que o petróleo só serve como combustível está, há muito tempo, ultrapassada, tendo em vista que tal recurso também é utilizado como matéria prima para os mais diversos produtos, como calçados e, até mesmo, como cosméticos. Nosso estudo trata do petróleo pelo seu conceito específico, não pelos seus derivados, levando em consideração nosso foco na produção (exploração, terminação, produção propriamente dita e refino) do mesmo.

O petróleo é por definição um combustível fóssil. Líquido oleoso, rico em hidrocarbonetos, principalmente alcanos. Esse combustível é encontrado no subsolo, não como uma espécie de rio subterrâneo ou camada líquida entre as rochas sólidas, mas sim impregnado nas rochas sedimentares, em profundidades que variam de poucos metros da superfície, chegando até mesmo a mais de $3 \mathrm{~km}$ abaixo da superfície, tanto em terra firme, quanto em terras submersas (THOMAS et al., 2004). Percebemos, neste conceito, características químicas e geológicas do petróleo e seu processo de formação, que são de suma importância para a produção do mesmo.

Para Bozelli et al. (2008), o petróleo constitui a principal fonte de energia utilizada pela sociedade contemporânea, apesar de ser um recurso natural não renovável. A exploração do mesmo tem gerado impactos ao ambiente e com isso tem exigido um processo de licenciamento 
ambiental, que determina medidas para minimizar esses impactos. Neste conceito, percebemos a ênfase do autor nos impactos ambientais gerados pela exploração do petróleo, que, de fato, é a fase da produção mais impactante ao meio ambiente. Porém, neste estudo não são desconsiderados os impactos gerados pelas demais fases da produção (terminação, produção propriamente dita e refino).

No estudo em pauta, procuramos entender o petróleo como sendo:

um líquido viscoso, em geral de coloração escura, que ocorre naturalmente, cuja composição química varia de lugar para lugar. Em geral, contém compostos de enxofre, oxigênio, nitrogênio, metais e outros elementos. É formado por uma mistura de diferentes hidrocarbonetos com diferentes pontos de ebulição, sendo matéria-prima de grande importância para a economia (MILLIOLI, 2008, p. 29).

Ressaltamos que, esse líquido viscoso tem sido produzido desigualmente pelo mundo afora e vem sendo transportado através dos oceanos e oleodutos e, em função dessa grande movimentação, há riscos de contaminação tanto no solo e no ar quanto no mar, causando danos ao meio ambiente.

Enfatizamos ainda que, entendemos por produção de petróleo, como sendo uma fase constituinte da indústria petrolífera, a qual compreende a exploração, a terminação, a produção propriamente dita e o refino do mesmo. A produção de petróleo pode ocorrer em terra (onshore) e em mar (offshore). É importante diferenciar o termo produção do de produção propriamente dita. A produção propriamente dita está inserida na etapa de produção de petróleo, e ela só acontece no caso do campo se revelar comercial, ou seja, se a partir dos estudos constituintes da exploração e da terminação for constatada uma viabilidade comercial para a produção de petróleo num determinado poço (KIMURA, 2005).

\subsection{IMPACTO AMBIENTAL}

É comum lembrarmos as palavras poluição e degradação quando se fala em impacto ambiental. Apesar de estarem relacionadas ao real conceito do termo, tais palavras remetem-se apenas a conotação negativa do mesmo. Sabemos que o impacto ambiental também pode ser positivo, o que aumenta ainda mais a abrangência do seu conceito, por isso, através da comparação entre as ideias de alguns autores, buscamos suporte para o esclarecimento das nossas ideias, o que contribuiu para o embasamento deste estudo.

De acordo com a NBR ISO 14.001, impacto ambiental consiste em qualquer modificação do meio ambiente, adversa ou benéfica, que resulte, no todo ou em parte, dos aspectos ambientais da organização (ABNT, 2004). Por se tratar de uma norma nacional, o conceito pertencente a ela é bastante utilizado pelas indústrias.

O Conselho Nacional do Meio Ambiente (CONAMA) define impacto ambiental, em sua resolução no 001/86, como sendo qualquer alteração das propriedades físicas, químicas e biológicas do meio ambiente, causada por qualquer forma de matéria ou energia resultante das atividades humanas que, direta e indiretamente, afetam: a saúde, a segurança e o bem-estar da população; as atividades sociais e econômicas; a biota; as condições estéticas e sanitárias do meio ambiente e; a qualidade dos recursos ambientais (BRASIL, 1986). 
Por outro lado, impacto ambiental pode ser compreendido como sendo uma "alteração da qualidade ambiental que resulta da modificação de processos naturais ou sociais provocada por ação humana" (SANCHÉZ, 2006, p.31-32). Percebemos a concordância deste conceito com o estabelecido pelo CONAMA, em que ambos enfatizam que o homem é o agente causador dos impactos e citam as questões sociais.

Por sua vez, Barbieri (2007) entende que o impacto ambiental resulta de qualquer mudança no ambiente natural e social decorrente de uma atividade ou de um empreendimento proposto. Esse autor ressalta que, mesmo considerando que mudanças podem ocorrer por causas naturais, as interessantes aqui são as resultantes de ações humanas.

Após a exposição de diferentes concepções sobre o que é impacto ambiental, optamos por tratá-lo como sendo uma alteração do homem (relacionadas a fins econômicos, ou não) sobre o ecossistema, que afeta, positiva ou negativamente, as relações sociais humanas e/ou as características físicas e biológicas do meio.

\section{HISTÓRIA DO PETRÓLEO NO MUNDO E NO BRASIL}

O petróleo é conhecido desde o período da antiga Babilônia, por volta do século III a. C. sendo utilizado na produção de tijolos. Por sua vez, índios pré-colombianos utilizavam o petróleo como impermeabilizador de potes cerâmicos e para pavimentação de ruas (THOMAS et al., 2004). O aparecimento do petróleo acontecia a partir de vazamentos naturais e eram usados de várias formas, como por exemplo, no embalsamento de mortos ilustres pelos egípcios, na pavimentação de estradas pelos Incas, para fins bélicos por gregos e romanos, entre outras.

Os métodos de obtenção do líquido viscoso eram bem primitivos, pois não havia um grande conhecimento sobre esse óleo, já que as principais matérias-primas utilizadas na época eram o óleo de baleia, carvão e alcatrão. Com o passar do tempo foram descobertos suas diversas finalidades, como o querosene a partir da destilação do petróleo que era bem mais barato, o que revolucionou a sociedade da época (THOMAS et al., 2004).

A indústria petrolífera moderna tem origem por volta de 1850, quando o escocês James Young, descobriu que o petróleo podia também ser extraído do carvão e xisto betuminoso, e então elaborou processos para sua criação (PAZ, J. C.; ALCINO, M., 2001, apud PORTALBRASIL, 2010). Já no período da segunda revolução industrial o petróleo passou a ser utilizado comercialmente, além do uso como combustível de base para o funcionamento dos meios de produção. Com a posterior criação e crescimento da indústria automobilística e aviadora, o petróleo passou a ser cada vez mais explorado, devido seu uso como combustível. As grandes guerras mundiais movimentaram maciçamente as indústrias bélicas, devido à necessidade de armas para combate. Além da grande quantidade de combustível necessária para movimentação das grandes máquinas de guerra. Somados todos esses motivos, o petróleo tornou-se o principal produto estratégico do mundo moderno, sedimentando-se de vez como matriz energética (THOMAS et al., 2004).

No século $\mathrm{XX}$, as companhias multinacionais cresceram exponencialmente, formaram verdadeiros impérios monopolizando todas as zonas produtoras de petróleo espalhadas pelo mundo, mas concentradas basicamente no Oriente Médio. A supremacia dessas companhias ficou conhecida como o grupo das "sete irmãs"; Exxon, Chevron, Móbil, Texano, Gulf, British Petroleum e Shell. 
O investimento em novas tecnologias proporcionava o aumento da qualidade e rendimento do petróleo. Os Estados Unidos detinham $50 \%$ da produção mundial e se viram ameaçados com o desenvolvimento notável de produção no Oriente médio. As atividades exploratórias se intensificaram com novos projetos de brocas e técnicas de perfuração que alcançaram a profundidade de 1000 metros no início do século XX. Esse avanço tecnológico permitiu maiores experiências offshore. Essas experiências foram muito proveitosas já que as plataformas continentais possuíam grande quantidade de matéria orgânica sedimentada e, por conseguinte petróleo.

O petróleo tinha e tem um grande poder econômico e nos anos 70 os preços dele aumentaram drasticamente o que tornou viável descobertas em novos lugares, entre eles no Mar do Norte e no México, enquanto os Estados Unidos viam suas grandes reservas se extinguirem, e precisavam de novas descobertas para suprir suas necessidades. Nas décadas de 80 e 90 foi possível a consolidação da tecnologia que diminuiu os custos da prospecção e produção em $60 \%$ (THOMAS et al., 2004).

Nos dias atuais, o petróleo tem muitas utilidades além do uso como óleo ou gasolina. Com o advento da petroquímica, novos compostos foram produzidos, dentre eles, são comumente usados diariamente: plásticos, tintas, corantes adesivos, detergentes, explosivos, cosméticos, etc.

No que se refere à história de produção de petróleo no Brasil, podemos afirmar que:

Começa em 1858, quando o Marquês de Olinda assinou o Decreto $n^{\circ} 2.266$ concedendo a José Barros Pimentel o direito de extrair minerais betuminosos para a fabricação de querosene, em terrenos situados às margens do Rio Marau, na então província da Bahia (THOMAS et al., 2004, p. 3).

Entretanto, ainda para Thomas et al. (2004), só em 1891 é que foram realizadas as primeiras pesquisas sobre a existência de petróleo no Brasil, especificamente no estado de Alagoas, devido a presença de sedimentos betuminosos. Mais tarde, nos anos de 1897, ocorre a perfuração do primeiro poço que, situado no estado de São Paulo e perfurado pelo fazendeiro Eugênio Ferreira de Camargo, produziu 0,5 $\mathrm{m}^{3}$ de óleo.

O país, antes de chegar a atual Petrobras, passou por vários órgãos relacionados às questões petrolíferas e minerais nacionais. Um desses Órgãos foi o Serviço Geológico e Mineralógico do Brasil, 1919, que atuou na perfuração de 63 poços nos estados de Alagoas, Pará, Bahia, São Paulo, Paraná, Santa Catarina e Rio de Janeiro, sem sucesso. Dessa forma, entra em atuação, em 1938, o Departamento Nacional de Produção Mineral, que não só constatou a presença de petróleo no Brasil como perfurou 80 poços e descobriu o primeiro campo de exploração comercial, em 1941, no estado da Bahia. Em decorrência de tamanhas descobertas, foi criado, também, o Conselho Nacional do Petróleo, responsável pela definição da política petrolífera (THOMAS et al., 2004).

Com o aumento do conhecimento geológico, a maior demanda por derivados de petróleo, concorrência das empresas internacionais e grandes parcelas de capital investido, desde a descoberta da existência de petróleo em território brasileiro, muito evoluiu a exploração de tal recurso energético no país. Para viabilizar esta exploração, em 1953, foi instituído o monopólio estatal do petróleo, o que culminou na criação da Petrobras, instalada um ano depois, que, além de gerenciar, teria a responsabilidade desse segmento da indústria nacional (PETROBRAS, 2012). 
Além de várias descobertas nos anos de 1961 é fundada para a indústria brasileira a primeira refinaria nacional, a Refinaria de Duque de Caxias. Hoje, tal refinaria é umas das mais importantes do Sistema Petrobras e, tendo aproximadamente $13 \mathrm{~km}^{2}$, é responsável por cerca de 1,2 bilhões de reais por ano em impostos pagos ao governo. Posteriormente, em 1967, teve início o setor petroquímico nacional e, em 1968, a primeira descoberta de petróleo no mar, assim como a implantação da primeira plataforma de perfuração (PETROBRAS, 2012).

Os anos 70 são marcados pela criação da Petrobras Distribuidora, com o propósito de comercializar, distribuir e industrializar derivados de petróleo e outros produtos, para viabilizar o desenvolvimento nacional, pela crise do petróleo, provocada pelo aumento drástico dos preços internacionais do mesmo, e pelo início da preocupação ambiental.

De acordo com a Petrobras (2012), a descoberta do Campo de Marlin e do Campo de Albacora, na Bacia de Campos, e a criação do programa de capacitação tecnológica em águas ultraprofundas ${ }^{2}$, que possibilitaram a exploração em profundidades cada vez maiores, marcaram a década de 80 . Já na década de 90 , a produção de petróleo no Brasil era superior a $182.000 \mathrm{~m}^{3} / \mathrm{dia}$ e, em 1997, termina o monopólio estatal do petróleo e a Petrobras torna-se uma das maiores empresas parcialmente privadas do mundo.

O século XXI traz consigo ainda mais avanços para a história petrolífera nacional. O país conquista sua autossuficiência na produção de petróleo e gás, com uma produção média de 1,9 milhões de barris por dia, e já são registradas explorações em profundidades superiores a 6.000 metros. Mesmo com tamanhas inovações e melhorias, ainda um ponto muito relevante para a exploração de petróleo nacional vem sendo a exploração no pré-sal. A produção do pré-sal, como já assinalamos na introdução, vem o número de reservas nacionais e colocará a nação em uma posição privilegiada no ranking das grandes empresas de energia do mundo (PETROBRAS, 2012).

\section{A INFLUÊNCIA DO PETRÓLEO NA MATRIZ ENERGÉTICA BRASILEIRA}

Entendemos que a matriz energética é toda energia disponibilizada para transformação, distribuição e utilização nos processos produtivos. É uma representação quantitativa da oferta de energia, ou seja, da quantidade de recursos energéticos oferecidos por um país ou por uma região (ARCADIS TETRAPLAN, 2012). Por sua vez, a Matriz brasileira é caracterizada pela grande participação do petróleo, assim como no resto do mundo, além da intensificação dos estudos quanto a novas tecnologias e energias alternativas.

O século XX significou um grande crescimento populacional e da demanda energética brasileira. Sendo o petróleo a energia propulsora para o desenvolvimento econômico baseado nos conceitos revolucionários industriais. Esse crescimento da população atrelado à adesão de um sistema capitalista industrial estimulou a produção de energia, fazendo com que os gastos com importação de petróleo e outras energias fossem diminuídos, a fim de baratear as mercadorias aqui produzidas e assim poder competir com o mercado internacional. Abaixo está situada a tabela

\footnotetext{
${ }^{2}$ Convém destacar que, para que a Petrobras conseguisse descobrir reservas e operar com eficiência em águas ultraprofundas, foram desenvolvidas tecnologias próprias e teve a contribuição de universidades e centros de pesquisa do país. Essa empresa contratou sondas de perfuração, plataformas de produção, navios, submarinos, com recursos que tem movimentado toda a cadeia da indústria de energia. Devido isso, os investimentos na área do pré-sal tem se ampliado atualmente, ficando em torno de US\$ 82 bilhões até 2018, de acordo com nosso Plano de Negócios da Petrobras (PETROBRAS, 2014).
} 
1 que mostra a extração, importação, exportação e consumo aparente de petróleo bruto entre os anos de 1935 e 1985 :

Tabela 1 - Extração, importação, exportação e consumo aparente de petróleo bruto 1935-85

\begin{tabular}{ccccc}
\multicolumn{5}{c}{ PETRÓLEO BRUTO $\left(\mathbf{1 0 0 0} \mathbf{~ m}^{\mathbf{3}}\right)$} \\
\hline ANOS & Extração & Importação & Exportação & Consumo aparente \\
\hline $\mathbf{1 9 3 5}$ & - & 3 & - & 3 \\
\hline $\mathbf{1 9 4 5}$ & 12 & 12 & - & 24 \\
\hline $\mathbf{1 9 5 5}$ & 321 & 4052 & - & 4373 \\
\hline $\mathbf{1 9 6 5}$ & 5460 & 11819 & - & 17279 \\
\hline $\mathbf{1 9 7 5}$ & 9979 & 39916 & 792 & 49103 \\
\hline $\mathbf{1 9 8 5}$ & 31709 & 30909 & - & 62618
\end{tabular}

Fonte: (IBGE, 2012, apud IBGE, 1990), adaptado.

A partir dos dados dessa tabela, tomando por base o período de 1935 a 1985, a extração do petróleo foi intensificada através do avanço da tecnologia de prospecção que possibilitou seu aumento expressivo no ano de 1985 em decorrência da grande descoberta de poços de petróleo. Já a importação foi aumentada no período de 1935-1975 pela crescente necessidade de abastecimento do setor industrial e do mercado automobilístico, mas no período de 1975-1985 essa importação foi diminuída pelo aumento da capacidade de produção de petróleo no Brasil. Por sua vez, a exportação do óleo cru, que era considerada nula pela baixa produção no intervalo de tempo de 1935-1975, foi aumentada no ano de 1975 pela geração excedente do óleo sendo posteriormente diminuída até a extinção, pela necessidade de direcionamento de todo o petróleo produzido para o mercado interno.

Os crescentes aumentos nas perspectivas de petróleo, configuradas até o ano 2000, consolidaram o grande aumento da extração desse combustível fóssil, como exposto no gráfico 1, a seguir, que apresenta o crescimento da perspectiva de petróleo entre os anos 1983-2000.

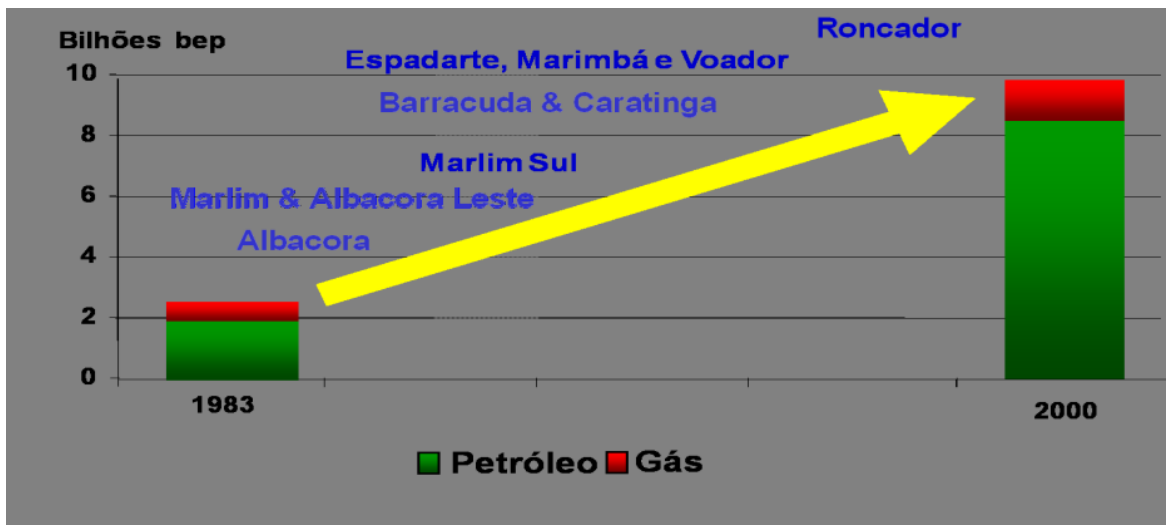

Gráfico 1 - Perspectivas na oferta de hidrocarbonetos, reservas provadas Fonte: Anuário Estatístico ANP (2001).

O gráfico 1 mostra que o número de reservas provadas de gás natural e petróleo praticamente quadruplicou no período de 1983 a 2000, provando o aumento da tecnologia de prospecção e perfuração. A participação do petróleo na matriz energética brasileira está diminuindo pela crescente utilização das energias alternativas. Pois, segundo dados da Petrobras, a previsão é de que o petróleo corresponda a $29 \%$ da matriz energética mundial em 2030, a correspondência foi de 33\% em 2008 (PETROBRAS, 2010). Isso comprova uma diminuição de $4 \%$ da participação desse combustível fóssil entre o período de 2008-2030. 
Essa crescente diminuição da exploração de petróleo e a busca por outras energias são explicadas pelo fato do petróleo ser um combustível fóssil, que polui o ar através de emissões gasosas, as quais reagem com o ar atmosférico formando compostos que potencializam o efeito estufa e prejudicam a camada de ozônio. Como o século XXI se baseia nas políticas da sustentabilidade e diminuição de impactos ambientais, a pesquisa e uso de energias alternativas é cada vez mais utilizada e desenvolvida. A grande maioria dessas energias são biocombustíveis na forma de óleos, que atuam como elementos substitutivos ao petróleo que apresentam menos moléculas de carbono em sua composição e, por conseguinte tem menor potencial de emissão de $\mathrm{CO} 2$ na atmosfera. Por sua vez, as energias Eólica e Solar apresentam-se como a alternativa mais sustentável no contexto atual, pois tem níveis de emissões de poluentes nulos, além do grande potencial de produção e transformação no contexto atual industrial.

A participação de fontes renováveis de produção de eletricidade na matriz elétrica do Brasil chegou a $88,8 \%$ em 2011, um aumento de 2,5\% em relação a 2010, segundo dados do Balanço Energético Nacional 2012. (CARTA VERDE, 2012).

O gráfico 2 apresenta a participação de energias renováveis na matriz energética brasileira, comparando-se a distribuição pelo mundo e em relação aos países da OCDE, disponibilizado no ano de 2012, mas referente ao ano de 2011.

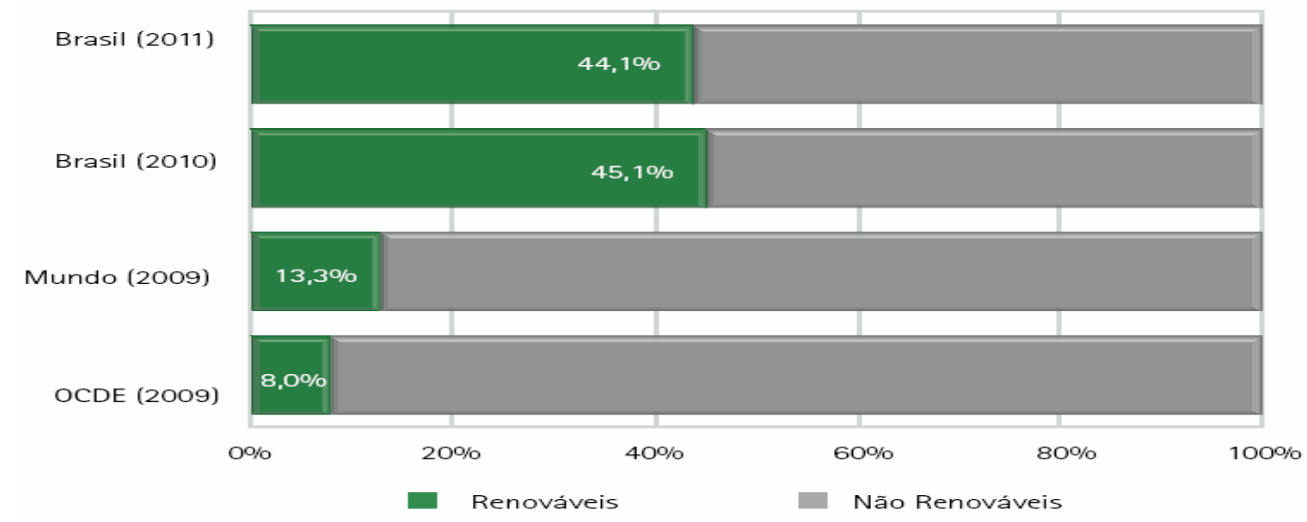

Gráfico 2 - Participação de energias renováveis, como um todo, na matriz energética FONTE: Empresa de Pesquisa Energética (2012).

Diante dessa participação, podemos perceber a difusão das energias alternativas em relação as não renováveis, não sendo mais o hidrocarboneto a única e exclusiva forma de obtenção de energia. Além da apresentação do grande avanço da conscientização socioambiental e tecnológico do Brasil, em comparação com o resto do mundo, pois o território brasileiro tem como constituinte de sua matriz cerca de três vezes mais energias renováveis que no resto do mundo, nesse intervalo de tempo. O que prova, então, a contribuição para a sustentabilidade, preservação e conscientização de como intervir no meio ambiente.

\section{OS PROCESSOS DE PRODUÇÃO DE PETRÓLEO}

A produção de petróleo é uma etapa da indústria petrolífera composta pela união de fases, as quais compreendem desde os estudos e testes necessários para a obtenção do óleo bruto, até a transformação do mesmo em seus produtos finais, como querosene, óleo diesel e gasolina. Este 
estudo tratará das seguintes fases da produção do petróleo: exploração, terminação, produção propriamente dita e refino.

\subsection{EXPLORAÇÃO}

A atividade de exploração de petróleo é feita com base em estudos técnicos e geológicos na busca de intensificar e aperfeiçoar as descobertas de novos poços de petróleo, mas mesmo com todo esse avanço tecnológico nos estudos geológicos e na perfuração, ainda é uma atividade que pode ser considerada essencialmente arriscada e de custo elevado. Os estudos para constatação da possibilidade de existência de petróleo são produzidos através de geofísica, sismologia, e tecnologias sofisticadas, como a perfuração e sondagem. Após a identificação, as jazidas descobertas devem ser avaliadas quanto ao tamanho e capacidade de produção a fim de descobrir ser rentável ou não sua exploração (KIMURA, 2005).

A exploração pode ser dividida em duas partes, em terra (onshore) e em mar (offshore). A tecnologia usada em ambas se distingue pela maior necessidade da mesma na exploração offshore devido a maior dificuldade de retirada o óleo do fundo do mar, pois o mesmo sem encontra em altas profundidades.

Outra ferramenta utilizada na fase inicial de exploração é a sísmica, que compreende pequenos terremotos artificiais, provocados geralmente através de explosivos, produzem ondas sonoras que são interpretadas na busca de formações geológicas típicas de armadilhas para o petróleo. Atualmente, utilizase a sísmica tridimensional que permitiu um aumento da velocidade e precisão da exploração sísmica. Além de permitir uma visualização dos mapas de qualquer ângulo, facilitando desta forma as análises dos dados. (KIMURA, 2005, p. 27).

A sísmica é uma das principais formas de detecção de poços através da prospecção. Ela se divide em três fases sendo a primeira fase caracterizada basicamente por um levantamento de dados geológicos. A segunda fase trata do processamento dos dados levantados para a posterior análise da estrutura geológica do subsolo. Já a terceira fase da sísmica é a interpretação do perfil geológico das áreas analisadas para determinar se dever haver ou não perfuração. Estes estudos são de grande importância, para determinar com algum grau de precisão onde se encontram os reservatórios de petróleo e gás (KIMURA, 2005 apud ALMEIDA, 2003).

Após as atividades sísmicas são instalados os equipamento voltados para a perfuração dos poços de petróleo, para o inicio da retirada do óleo. A perfuração se caracteriza pelas altas tecnologias usadas nas brocas e sondas que apresentam vários tipos. As primeiras sondas utilizavam a técnica de perfuração por percussão, ou seja, as sondas são içadas por cabos e perfuravam o solo através do impacto de seu peso no solo. Atualmente, existem vários tipos de brocas, tal como a broca de roletes (ou Tricone), brocas de diamante e a broca de lâmina. $O$ tipo de broca utilizada depende das condições específicas do solo. (KIMURA, 2005 apud ALMEIDA, 2003).

Depois de perfurado o terreno, motores são instalados para bombear o óleo até a superfície. Tanto nesse trajeto como no processo de perfuração além do de bombeamento, os cuidados com a segurança atingem patamares altíssimos, pois o risco de derramamento é eminente, o que acontecendo, prejudicaria a concessionária quanto à continuidade da licença de operação além do grande prejuízo com multas e processos. 
O registro de todas as atividades e estudos referentes aos poços em produção, ou não, serve para o enriquecimento do conhecimento da estrutura geológica dos terrenos e sua propensão à produção de petróleo. Facilitando assim, com o avanço da tecnologia, o trabalho na exploração de poços mais profundos e uma maior velocidade no processo, já que, ao invés de ser feito um novo estudo, pode-se fazer apenas uma checagem das informações já existentes.

\subsection{TERMINAÇÃO}

Terminação consiste na fase de produção de petróleo posterior à perfuração, na qual ocorrem às análises dos dados obtidos durante a perfuração e alguns testes complementares são realizados. Além das fases testes, a terminação engloba a parte de completação do poço. Parte esta que deixa o poço apto para a fase de produção em si (THOMAS et al., 2004).

\subsubsection{Teste e avaliações de formação}

Após a fase de exploração são realizados vários estudos e testes que visam definir, em dados qualitativos e quantitativos, o real potencial da reserva petrolífera e, desse modo, avaliar a capacidade econômica desse poço. (THOMAS et al., 2004).

Para obtermos tais avaliações são utilizados, além dos registros já existentes da fase de exploração, a perfilagem a poço aberto, os testes de pressão a poço revestido e a perfilagem de produção.

- Perfilagem a poço aberto: De acordo com Drummond (2012), chama-se perfilagem o levantamento completo de perfis referentes ao poço de exploração. O perfil de um poço é a imagem visual, em relação à profundidade, de uma ou mais características ou propriedades das rochas perfuradas (resistência elétrica, potencial eletroquímico natural, tempo de trânsito de ondas mecânicas, radioatividade natural, entre outros).

- Testes de pressão: Em virtude da presença de uma pressão estática original no reservatório e, durante o período produtivo, ocorrer a existência de variações dessa pressão, são realizados testes de pressão com o intuito de identificar os fluidos contidos na formação, os parâmetros da formação e dos danos da formação, a produtividade da formação, entre outros.

- Perfilagem de produção: Para Thomas et al. (2004) a perfilagem de produção tem como objetivo definir a efetividade de uma completação ou as condições de produtividade de um poço. É realizada após a análise dos perfis ocorridos após a descida do revestimento de produção e completação do poço.

\subsubsection{Completação}

Ao termino da fase de perfuração de um poço e durante todo o seu ciclo produtivo são necessárias condições de operação que apresentem segurança e sejam viáveis economicamente. Diante dessas condições, dar-se o nome de completação ao conjunto de operações destinadas a equipar o poço para sua produção (THOMAS et al., 2004).

Para a elaboração dessas completações são necessários altos graus de precisão e análise, já que requer altos custos e se prolonga durante toda a exploração do poço. É fundamental visar a otimização do poço e tentar estabelecer baixos custo com a manutenção. 
Em virtude da complexidade da completação, podemos dividir essa etapa do processo de produção em diferentes tipos, que são, de acordo com Thomas et al. (2004), quanto ao posicionamento da cabeça do poço (na superfície ou submersas); quanto ao revestimento de produção (poço aberto, com linear rasgado ou canhoneado e com revestimento canhoneado) e quanto ao número de zonas exploradas (simples ou múltiplas).

Além dos tipos de completação, existem ainda as etapas da mesma (instalação dos equipamentos de superfície, condicionamento do poço, avaliação da qualidade da cimentação, canhoneio, instalação da coluna de produção e colocação do poço em produção), os principais componentes da coluna de produção (tubos de produção, shear-out, hydro-trip, nipples de assentamento, camisa deslizante, check valve, packer de produção, unidade selante, junta telescópica e mandril de gas-lift), os equipamentos de superfície (cabeça de produção, árvore de natal convencional e árvore de natal molhada) e as intervenções no poço, que podem ser por falhas mecânicas, restrições que diminuam a produção, grandes quantidades de gás, água ou areia (THOMAS et al., 2004).

\subsection{PRODUÇÃO}

A fase de produção consiste na retirada do óleo cru dos reservatórios com a finalidade de transporta-lo para o refino, e posteriormente comercializar o produto final. A produção só ocorre no caso do campo se revelar comercial, ou seja, se a partir dos estudos constituintes da exploração e da terminação for constatada uma viabilidade comercial para a produção de petróleo num determinado poço (KIMURA, 2005).

Para a fase de produção são empregadas técnicas de surgência, técnicas primárias, para a fluidez do material à superfície e, caso haja ineficiência dessas técnicas ao decorre da produção, são utilizadas técnicas secundárias, também chamadas de recuperação secundária, para otimizar a produção no poço.

\subsubsection{Técnicas primárias de produção}

Com o término da fase de completação, o poço encontra-se com todos os equipamentos necessários para a realização da extração em si e para o início da fase de produção. Entretanto, são necessários mecanismos que possibilitem o fluxo de fluidos do fundo do poço até a superfície. Os métodos utilizados para a extração desses fluidos podem ser divididos em naturais e artificiais, já que, segundo Corrêa (2003), caso os fluidos não necessitem de nenhuma energia externa, com exceção da natural do poço, para chegar à superfície, são considerados poços de surgência natural e, caso haja a necessidade de aplicar uma energia externa para que os fluidos atinjam a superfície, temos um poço de surgência artificial.

Para a elevação artificial ocorrer, foram projetados vários sistemas que vão desde grandes e complexos maquinários até mecanismos leves e flexíveis, apresentando várias peculiaridades entre si. Alguns desses sistemas são: bombeio mecânico por hastes; bombeio hidráulico de superfície; bombeio elétrico submerso; sistema de gás-lift; Elevação a êmbolo livre. (CORRÊA, 2003) 
Em todos esses sistemas de elevação artificial (surgência artificial) podemos apontar vantagens e desvantagens para sua execução. Admitindo tal possibilidade, temos o disposto no quadro 1.

Quadro 1 - Vantagens e desvantagens dos sistemas de elevação artificial.

\begin{tabular}{|c|c|c|}
\hline SISTEMAS DE ELEVAÇÃO ARTIFICIAL & VANTAGENS & DESVANTAGENS \\
\hline BOMBEIO MECÂNICO POR HASTES & $\begin{array}{l}\text { - Pode usar gás e eletricidade; } \\
\text { - Pode elevar óleos de alta } \\
\text { temperatura e viscosidade; } \\
\text { - Pode bombear um poço de } \\
\text { baixa pressão. }\end{array}$ & $\begin{array}{l}\text { - Alta produção de sólidos; } \\
\text { - Modifica consideravelmente a } \\
\text { paisagem onde é implantado; } \\
\text { - Poços tortuosos apresentam } \\
\text { problemas. }\end{array}$ \\
\hline $\begin{array}{l}\text { BOMBEIO HIDRÁULICO DE } \\
\text { SUPERFÍCIE }\end{array}$ & $\begin{array}{l}\text { - Pode elevar grandes volumes; } \\
\text { - É flexível; } \\
\text { - Bombeia poços com pressões } \\
\text { muito baixas. }\end{array}$ & $\begin{array}{l}\text { - Grande produção de sólidos; } \\
\text { - Requer desabafadores de gás; } \\
\text { - Altos custos operacionais. }\end{array}$ \\
\hline BOMBEIO ELÉTRICO SUBMERSO & $\begin{array}{l}\text { - Simples de operar; } \\
\text { - Não obstrui em locações } \\
\text { urbanas; } \\
\text { - Poços tortuosos não } \\
\text { apresentam problemas. }\end{array}$ & $\begin{array}{l}\text { - Somente utiliza energia elétrica; } \\
\text { - Produção de gás e de sólidos é } \\
\text { problemática; } \\
\text { - Difícil analise dos dados. }\end{array}$ \\
\hline SISTEMA DE GÁS-LIFT & $\begin{array}{l}\text { - Elevação em poços com } \\
\text { muito gás não é problema; } \\
\text { - Ampla capacidade de } \\
\text { abastecimento energético; } \\
\text { - Manuseio de grandes } \\
\text { volumes de óleo. }\end{array}$ & $\begin{array}{l}\text { - Problemas com sujeira nas } \\
\text { linhas de superfície; } \\
\text { - Problemas de segurança devido } \\
\text { ao gás em alta pressão; } \\
\text { - Não é eficiente em pequenos } \\
\text { campos. }\end{array}$ \\
\hline ELEVAÇÃO A ÊMBOLO LIVRE & $\begin{array}{l}\text { - Instalação pouco onerosa; } \\
\text { - Pode ser recuperável sem a } \\
\text { retirada da tubulação; } \\
\text { - Pode ser utilizado em junção } \\
\text { com o gás-lift. }\end{array}$ & $\begin{array}{l}\text { - Existe o risco de danos a } \\
\text { superfície; } \\
\text { - Só é utilizado em poços de baixa } \\
\text { vazão; } \\
\text { - Maior necessidade de } \\
\text { supervisão. }\end{array}$ \\
\hline
\end{tabular}

Fonte: adaptado de Corrêa (2005).

Dessa forma, com a análise do quadro 1, é notável que, mesmo com as vantagens de cada sistema, a presença de inúmeras desvantagens nos sistemas de elevação artificial são elementos de potencial risco para acidentes, em virtude dessa situação, tem-se a necessidade de melhorias nesses sistemas para diminuir tais riscos e otimizar os sistemas no que diz respeito ao setor ambiental.

\subsubsection{Recuperação secundária}

Para Corrêa (2005), é considerada recuperação secundária de um campo de petróleo, às técnicas utilizadas, nos reservatórios, para recuperar o óleo que não se conseguiu retirar pelos processos de surgência naturais e artificiais. Entre as técnicas convencionais empregadas para a recuperação secundária, encontramos a injeção de água e a injeção de gás em poços injetores.

A injeção de água é um dos métodos mais utilizados no mundo. Como a água e o óleo não se misturam, através de um poço de injeção é aplicada água no reservatório para que a pressão gerada impulsione o óleo a subir. 
Já no processo onde ocorre a injeção de gás, é aplicado um método similar ao da injeção de água. Entretanto, para a utilização de gás são necessários alguns processos para torna-lo próprio para tal tarefa, o que acaba por deixar a sua utilização economicamente inviável.

\subsection{REFINO}

O refino de petróleo constitui a separação deste insumo, via processos físico-químicos, em fração de derivados, que são realizados em unidades de separação e conversão até os produtos finais, classificados como: combustíveis (gasolina, querosene, diesel, entre outros); produtos acabados não combustíveis (lubrificantes, asfalto e graxas); e intermediários da indústria química (propano, butano, nafta, etc.) (SZKLO, 2005).

O produto extraído na fase de exploração e produção é refinado nas refinarias, sistemas complexos com múltiplas operações que dependem das propriedades do insumo. Dentro das refinarias, as operações pelas quais o óleo é submetido podem ser divididas em: etapas de separação, conversão, tratamento e auxiliares, que serão definas adiante.

As separações são sempre de natureza física e desestruturam o petróleo em suas formas mais básicas, ou ainda tem a finalidade de processar uma fração previamente produzida para se obter um grupo específico de componentes (DIAS, 2010).

A conversão pode ser definida como:

Processos de natureza química que visam transformar uma fração em outra(s), ou alterar profundamente a constituição molecular de uma dada fração, de forma a melhorar sua qualidade, valorizando-a. Isto pode ser conseguido através de reações de quebra, reagrupamento ou reestruturação molecular. (PETROBRAS, 2002, p. 10).

Os processos de tratamento são de natureza química, tendo como objetivo não provocar profundas modificações nas frações, contudo promovem melhorias de qualidade de cortes semiacabados, eliminando ou reduzindo impurezas presentes (DIAS, 2010).

No caso dos processos auxiliares, podemos defini-los como:

Aqueles que se destinam a fornecer insumos à operação dos outros anteriormente citados, ou a tratar rejeitos desses mesmos processos. Incluem-se, neste grupo, a Geração de Hidrogênio (fornecimento deste gás às unidades de hidroprocessamento), a recuperação de Enxofre (produção desse elemento a partir da queima do gás ácido rico em H2S) e as utilidades (vapor, água, energia elétrica, ar comprimido, distribuição de gás e óleo combustível, tratamento de efluentes e tocha), que, embora não sejam de fato unidades de processo, são imprescindíveis a eles (PETROBRAS, 2002, p. 15).

Para uma melhor exposição dos possíveis processos encontrados nas etapas de separação, conversão, tratamento e processos auxiliares, temos disposto no quadro 2. 
Quadro 2 - Resumo dos processos do refino de petróleo.

\begin{tabular}{|c|c|c|}
\hline ETAPAS & TIPOS DE PROCESSO & PROCESSOS \\
\hline SEPARAÇÃO & Físico & $\begin{array}{l}\text { Destilação Atmosférica } \\
\text { Destilação a vácuo } \\
\text { Estabilização de naftas } \\
\text { Extração de aromáticos } \\
\text { Desasfaltação a propano } \\
\text { Desaromatização a furtural } \\
\text { Desparafinação a solvente } \\
\text { Desoleitificação a solvente } \\
\text { Absorção de N-parafinas }\end{array}$ \\
\hline CONVERSÃO & Químico & $\begin{array}{l}\text { Visco-Redução } \\
\text { Craqueamento Térmico } \\
\text { Coqueamento retardado } \\
\text { Craqueamento catalítico } \\
\text { Hidrocraqueamento } \\
\text { Reformação catalítica } \\
\text { Isomerização catalítica } \\
\text { Alquilação catalítica } \\
\text { Polimerização catalítica }\end{array}$ \\
\hline TRATAMENTO & Químico & $\begin{array}{c}\text { Dessalgação eletrostática } \\
\text { Tratamento cáustico } \\
\text { Tratamento Merox } \\
\text { Tratamento Bender } \\
\text { Tratamento DEA/MEA } \\
\text { Hidrotratamento }\end{array}$ \\
\hline $\begin{array}{l}\text { PROCESSOS } \\
\text { AUXILIARES }\end{array}$ & Químico & $\begin{array}{c}\text { Geração de hidrogênio } \\
\text { Recuperação de enxofre } \\
\text { Utilidades }\end{array}$ \\
\hline
\end{tabular}

Fonte: adaptado de Szklo (2005).

As etapas de separação, conversão e tratamento podem ser enquadrados, de acordo com os processos neles apresentados, em: Operações Topping; Craqueamento térmico; Combinação de hidrocarbonetos; Rearranjo de hidrocarbonetos; Tratamento e blending. (SZKLO, 2005)

\subsubsection{Operações topping}

Também podem ser apresentadas como operações de separação de hidrocarbonetos. Os fatores responsáveis por estas operações são físicos, por ação de energia (alterações na temperatura e/ou pressão) ou de massa (relações de solubilidade a solventes) sobre o petróleo ou suas frações. São comuns nessa operação a destilação atmosférica, a destilação a vácuo, a estabilização de naftas, extração de aromáticos, desasfaltação a solvente, desaromatização a furfural, desparafinação a solvente, desoleificação a solvente e absorção de N-parafinas. Entretanto, podemos resumir, como principais processos, a destilação e a desasfaltação a solventes (SZKLO, 2005).

\subsubsection{Craqueamento térmico}

Conhecido como catalítico de hidrocarbonetos, relaciona-se a quebra de moléculas grandes de hidrocarbonetos em moléculas menores. Para a obtenção dessa quebra de moléculas os hidrocarbonetos são expostos a determinadas frações de calor, podendo ter nesse processo a 
presença de catalisadores. Alguns exemplos de operações realizadas nessa etapa são a viscoredução e o termo-craqueamento (SZKLO, 2005).

\subsubsection{Combinação de hidrocarbonetos}

Para Szklo (2005), enquanto o craqueamento relaciona-se a quebra das moléculas, a combinação envolve a fusão de duas ou mais moléculas para originar uma molécula maior. Na etapa de combinação de hidrocarbonetos encontramos unidades de alquilação e polimerização.

\subsubsection{Rearranjo de hidrocarbonetos}

O rearranjo de hidrocarbonetos altera a estrutura original das moléculas, o que ocasiona uma nova molécula com diferentes propriedades físico-químicas, porém apresentando o mesmo número de átomos de carbono em sua organização. Nesse processo encontram-se as unidades de reformação catalítica e as de isomerização (SZKLO, 2005).

\subsubsection{Tratamento e blending}

Segundo Szklo (2005), é nesse processo onde há a remoção de enxofre, nitrogênio, metais pesados e outras impurezas. Além do que, ocorre nessa operação, o blending, a obtenção dos produtos finais, sendo essa a última etapa do processo de refino. É importante ressaltar a presença das unidades de recuperação de enxofre e as de hidrotratamentos nessa operação.

Após os processos de refino e da obtenção dos produtos finais, analisamos alguns aspectos ambientais presentes no refino do óleo, os quais estão dispostos no quadro 3.

Quadro 3 - Principais aspectos ambientais do processo do refino de petróleo quanto ao seu grau de risco.

\begin{tabular}{|cccc|}
\hline PROCESSOS & $\begin{array}{c}\text { EMISSÕES } \\
\text { ATMOSFÉRICAS }\end{array}$ & $\begin{array}{c}\text { EFLUENTES } \\
\text { LíQUIDOS }\end{array}$ & ESÍDUOS SÓLIDOS \\
\hline DESTILAÇÃO (ATMOSFÉRICA E A VÁCUO) & $\mathrm{A}$ & $\mathrm{A}$ & $\mathrm{B}$ \\
\hline TERMO-CRAQUEAMENTO & $\mathrm{A}$ & $\mathrm{A}$ & $\mathrm{B}$ \\
\hline COQUEAMENTO RETARDADO & $\mathrm{A}$ & $\mathrm{A}$ & $\mathrm{A}$ \\
\hline CRAQUEAMENTO CATALÍTICO & $\mathrm{A}$ & $\mathrm{A}$ & $\mathrm{A}$ \\
\hline HIDROCRAQUEAMENTO CATALÍTICO & $\mathrm{A}$ & $\mathrm{A}$ & $\mathrm{A}$ \\
\hline ISOMERIZAÇÃO & $\mathrm{A}$ & $\mathrm{A}$ & $\mathrm{A}$ \\
\hline ALQUINAÇÃO & $\mathrm{A}$ & $\mathrm{B}$ & $\mathrm{A}$ \\
\hline HIDRODESSULFRIZAÇÃO & $\mathrm{A}$ & $\mathrm{A}$ & $\mathrm{A}$ \\
\hline LAVAGEM DE GASES & $\mathrm{A}$ & $\mathrm{B}$ & $\mathrm{A}$ \\
\hline Legenda: A: alto; B: baixO. & & Fonte: adaptado de Szklo (2005). \\
\hline
\end{tabular}

Diante desses aspectos, expostos no quadro 3, podemos compreender que, mesmo com os mais variados processos a serem empregados nas etapas do refino, muitos são os aspectos ambientais gerados nesses processos que apresentam alto risco, o que acarretará em graves consequências ao meio ambiente, seja em seu meio físico, biológico ou antrópico. 


\section{CONSIDERAÇÕES SOBRE OS PRINCIPAIS IMPACTOS AMBIENTAIS}

A exploração e produção de petróleo, como outras atividades econômicas que utilizam recursos naturais, apresentam impactos ambientais positivos e negativos. Todas as etapas de produção da indústria petrolífera, desde a perfuração ao refino, causam impactos ao meio ambiente. Ao se falar em impacto ambiental, é comum que seja feita uma relação direta com grandes desastres ambientais acarretados pelo rompimento de oleodutos ou poços marítimos, os quais são sempre expostos pela mídia através de imagens de aves agonizando cobertas de óleo e peixes mortos, por exemplo. Porém, sabemos que o impacto ambiental tanto pode ser de caráter negativo quanto positivo. Não se pode negar o volume de negócios que proporcionados com o desenvolvimento da exploração e produção de petróleo, impulsionando toda a cadeia de bens e serviços, trazendo tecnologia, capacitação e grandes oportunidades de empregos e rendas.

A avaliação de impactos ambientais, de um determinado empreendimento, é feita a partir do diagnóstico ambiental da área de influência do mesmo, pois, através dele, é possível conhecer detalhadamente as características físicas, biológicas e socioeconômicas da área.

Após o conhecimento de tais características, são levantados os aspectos ambientais do empreendimento. De acordo com a NBR ISO 14001, aspectos ambientais consistem em elementos das atividades, produtos e serviços de uma organização que podem interagir com o meio ambiente (ABNT, 2004).

Dessa forma, conhecendo os aspectos ambientais, é possível, por meio de métodos de avaliação, analisarmos os impactos ambientais, levando em consideração os diferentes componentes ambientais dos meios físico, biológico e antrópico, conforme disposição apresentada no quadro 4.

Quadro 4-Componentes ambientais dos diferentes meios

\section{MEIO FÍSICO MEIO BIOLÓGICO MEIO ANTRÓPICO}

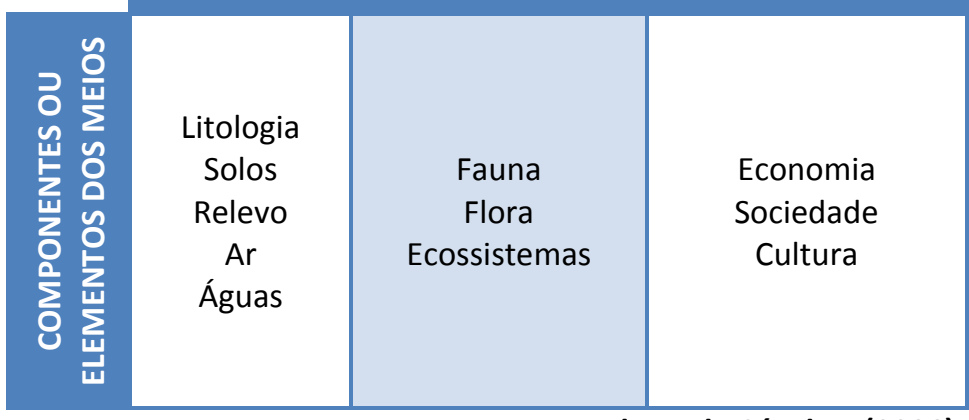

Fonte: adaptado Sánchez (2006).

Para a elaboração deste estudo, foi levado em consideração o processo de produção do petróleo, o qual envolve a exploração, a terminação, a produção propriamente dita e o refino. De uma forma geral, expomos os principais impactos ambientais do processo de produção de petróleo, baseados em estudos de impacto ambiental (EIAs) e relatórios de impacto ambiental (RIMAs), os quais estão dispostos de acordo com os meios físico, biológico e antrópico.

\subsection{MEIO FÍ́SICO}

Como visto no quadro 4, o meio físico compreende a litologia, o solo, o relevo, o ar e as águas; os quais são componentes constantemente degradados pela indústria petrolífera. Levando 
em consideração as etapas estudadas (exploração, terminação, produção e refino), foram constatados diversos aspectos ambientais, os quais estão dispostos no quadro 5 e são potencialmente causadores de impactos negativos ao meio físico.

Quadro 5 - Principais aspectos ambientais potenciais causadores de impactos negativos

\begin{tabular}{|ll|}
\multicolumn{1}{l}{ ASPECTOS AMBIENTAIS } \\
\hline 1. & Geração de cascalho e deposição ao redor da cabeça dos poços; \\
\hline 2. & Geração de efluentes domésticos e despejo no mar; \\
\hline 3. & Despejo de resíduos oleosos no solo e/ou mar; \\
\hline 4. & Má disposição de resíduos sólidos contaminados; \\
\hline 5. & Emissão de gases; \\
\hline 6. & Geração de ruídos e vibrações; \\
\hline 7. & Vazamentos de dutos e/ou tanques de armazenamento no solo e/ou mar; \\
\hline 8. & Colisões entre navios e despejo de óleo bruto no mar; \\
\hline 9. & Vazamento ou derramamento de resíduos da lavagem dos tanques de navios petroleiros; \\
\hline 10. & Despejos de rejeitos do processamento industrial. \\
\hline
\end{tabular}

Fonte: adaptado de Brasil (2010).

É importante ressaltar que alguns dos aspectos ambientais citados são responsáveis pelo mesmo impacto ambiental, diferenciando-se apenas na forma pela qual o poluente entra em contato com o meio.

Os principais impactos ambientais no meio físico, causados pela produção de petróleo, levando em consideração os aspectos ambientais citados, são: variação da qualidade das águas, variação da qualidade do ar e variação da qualidade do solo.

\subsubsection{Variação da qualidade das águas}

A variação da qualidade das águas durante a operação das atividades ocorre em função do lançamento de rejeitos na água do mar, tais como água de drenagem, líquidos de limpeza, efluente sanitário e restos alimentares. O lançamento de efluente sanitário e restos alimentares poderá promover o incremento temporário de matéria orgânica nas águas oceânicas. (BRASIL, 2010).

Por sua vez, os efluentes contaminados por substâncias químicas, como líquidos de limpeza e rejeitos do processamento industrial, ao entrarem em contato com o mar, modificam as características físico-químicas do mesmo, como a turbidez, que é aumentada, e a concentração de oxigênio dissolvido, que é reduzida (MATOS, 2010). Tais modificações afetam diretamente os seres bióticos presentes na área de influência da atividade, os quais serão aprofundados posteriormente.

\subsubsection{Variação da qualidade do ar}

Os impactos ambientais na qualidade do ar decorrem principalmente das emissões de gases vinculadas ao funcionamento de exaustores de máquinas e turbinas a diesel, e à queima de hidrocarbonetos durante o teste do poço, quando este é realizado (BRASIL, 2010).

As emissões atmosféricas geralmente são compostas de $\mathrm{NOx}, \mathrm{CO}, \mathrm{SO} 2, \mathrm{CO} 2, \mathrm{CH} 4$, $\mathrm{NO}$ e material particulado. Em todo processo de combustão, as emissões de dióxido de carbono (CO2) são inevitáveis. Esse gás não causa nenhum risco à saúde, no entanto, há grande preocupação com o seu efeito estufa, que na opinião de muitos cientistas está aumentando a temperatura do Planeta (BRASIL, 2011). 


\subsubsection{Variação da qualidade do solo}

A variação da qualidade do solo ocorre devido à remoção da cobertura vegetal presente para a instalação do poço. Com a remoção da cobertura vegetal, o solo perde a sua defesa natural e fica propício à erosão (SILVA; PEGADO, 2009). Além disso, há impacto no solo pela disposição de cascalhos contaminados por óleo, os quais são dispostos ao redor da cabeça dos poços.

Os efeitos potenciais da contaminação do solo por petróleo são relativamente moderados. Danos são causados à vegetação, mas a extensão espacial é relativamente restrita. Exceto em casos de grandes derramamentos, a área da terra que deve ser afetada é pequena, devido a grande capacidade da terra de absorção e a formação de blocos pelo óleo derramado que, dessa forma, não vai se distribuir enormemente (MATOS, 2010).

\subsection{MEIO BIOLÓGICO}

Todos os aspectos ambientais listados no quadro 5 causam interferência na biota, seja ela marinha ou terrestre. Essas interferências podem levar a fuga, ao estresse e/ou a perda de organismos.

Quando os manguezais são atingidos por óleo, o sistema radicular das plantas fica completamente impermeabilizado, tornando-as incapazes de absorver oxigênio e nutrientes. Nessas condições, os vegetais passam a perder as folhas e não conseguem realizar a fotossíntese. Os animais que habitam esses ecossistemas podem morrer em poucos dias por asfixia, enquanto outros podem ir se intoxicando aos poucos ao ingerirem alimentos contaminados. O óleo que cobre o corpo dos animais pode prejudicar o sistema de isolamento térmico de alguns, principalmente das aves, nas quais a camada de penas tem como importante função a de armazenar ar e gás de baixa condutividade térmica (MATOS, 2010).

No que se refere à exploração marítima, os organismos que mais sofrem interferência, de acordo os estudos de impactos ambientais observados, foram os componentes das comunidades planctônica e bentônica.

A redução da intensidade de luz no corpo d'água, provocada pelo aumento da turbidez pode influenciar, temporariamente, a capacidade fotossintética dos organismos fitoplanctônicos. Para o zooplâncton, as consequências do aumento da turbidez deverão estar relacionadas principalmente com a diminuição da concentração do fitoplâncton, ou seja, da oferta de alimento. Além disto, um possível impacto direto ocorreria sobre os organismos filtradores, que eventualmente poderiam ter seus aparatos filtradores entupidos pelos sólidos em suspensão, dificultando a alimentação (BRASIL, 2011).

Em relação à comunidade bentônica, o recobrimento do fundo pelo cascalho descartado pode causar a morte de organismos, principalmente do macro e megabentos, por soterramento e asfixia (BRASIL, 2010). O zoobentos poderá ter suas estruturas respiratórias e alimentares temporariamente afetadas pelo aumento de sólidos em suspensão e o fitobentos poderá ter sua capacidade fotossintética reduzida pelo aumento da turbidez (BRASIL, 2011).

\subsection{MEIO ANTRÓPICO}

O meio antrópico envolve todas as ações que se relacionam com a economia, a sociedade e a cultura. A exploração de petróleo causa diversos impactos a tal meio, sendo alguns deles, 
inclusive, positivos. Os principais impactos no meio antrópico estão dispostos no quadro 6, que relaciona os impactos a sua forma de ocorrência.

Quadro 6 - Principais impactos no meio antrópico e suas formas de ocorrência

\begin{tabular}{|c|c|}
\hline IMPACTOS & OCORRÊNCIA \\
\hline Geração de expectativas & $\begin{array}{l}\text { As expectativas positivas ocorrem especialmente com relação aos } \\
\text { royalties, a geração de empregos e ao estímulo à economia. As } \\
\text { negativas manifestam-se publicamente através da preocupação com } \\
\text { as questões ambientais e com as interferências na atividade } \\
\text { pesqueira e turística. }\end{array}$ \\
\hline $\begin{array}{l}\text { Atração de população e } \\
\text { aceleração da expansão do } \\
\text { espaço urbano }\end{array}$ & $\begin{array}{l}\text { Impacto sinérgico vinculado à atração de trabalhadores de outros } \\
\text { municípios ou até de outros estados, em relação à possibilidade de } \\
\text { obter emprego, com consequente aceleração da expansão urbana. }\end{array}$ \\
\hline $\begin{array}{l}\text { Pressão sobre a infraestrutura } \\
\text { urbana e social }\end{array}$ & $\begin{array}{l}\text { Aumento da demanda por infraestrutura regional em função da } \\
\text { presença dos empreendimentos. }\end{array}$ \\
\hline $\begin{array}{l}\text { Geração de renda, dinamização } \\
\text { da economia local e demanda de } \\
\text { bens e serviços }\end{array}$ & $\begin{array}{l}\text { Impacto sinérgico vinculado à geração de empregos por demanda de } \\
\text { serviços, promovendo contratação de bens e serviços. }\end{array}$ \\
\hline $\begin{array}{l}\text { Aumento da demanda por áreas } \\
\text { para destinação final de resíduos } \\
\text { sólidos }\end{array}$ & $\begin{array}{l}\text { Aumento da demanda por áreas em terra para disposição dos } \\
\text { resíduos a serem gerados pelas atividades de implantação dos } \\
\text { empreendimentos. }\end{array}$ \\
\hline $\begin{array}{l}\text { Aumento da produção nacional } \\
\text { de hidrocarbonetos }\end{array}$ & $\begin{array}{l}\text { Aumento da produção nacional de óleo e gás natural proveniente de } \\
\text { novas explorações. }\end{array}$ \\
\hline Repasse de royalties & $\begin{array}{l}\text { Incremento na arrecadação e contribuição da receita municipal } \\
\text { durante as atividades de produção e escoamento. }\end{array}$ \\
\hline Interferência na pesca & $\begin{array}{l}\text { Em geral, são relacionados à influência direta da exploração do } \\
\text { petróleo e alteração no pescado, seja pelo risco de acidentes e } \\
\text { vazamentos, ou em relação à área delimitada para a pesca junto às } \\
\text { plataformas de petróleo, que corresponde, segundo determinação } \\
\text { legal, a um raio de } 500 \mathrm{~m} \text { em torno da plataforma. }\end{array}$ \\
\hline
\end{tabular}

Fonte: adaptado de Brasil (2007).

Analisando o quadro 6, podemos observar a disposição dos principais impactos causados no meio antrópico. Podemos identificar facilmente alguns impactos de caráter positivo, como, por exemplo, o repasse de royalties, que é responsável pelo acréscimo de capital à receita municipal, e a geração de renda, que está relacionada à geração de empregos. Ambos os impactos contribuem para a melhoria da qualidade de vida da sociedade afetada pelo empreendimento, podendo ser considerados uma vantagem à mesma.

\section{CONSIDERAÇÕES FINAIS}

Após as pesquisas bibliográficas e documentais, sobre a produção de petróleo e impactos ambientais, concluímos que a produção de petróleo apresenta, em suas etapas, diversos aspectos ambientais, os quais são, de fato, causadores de impactos. Percebemos que alguns impactos são indissociáveis de algumas etapas, ou seja, para o desenvolvimento de algumas etapas, inevitavelmente, são causados impactos.

Concluímos também, que a fase de produção de petróleo não gera apenas impactos de caráter negativo, pois, como foi exposto, alguns impactos, como o repasse de royalties e a geração de empregos, por exemplo, contribuem para a melhoria da qualidade de vida da sociedade. 
Porém, ressaltamos que a gama de impactos ambientais de caráter negativo advindos da produção de petróleo, seja nos meios físico e biológico, ou até mesmo socioeconômico, devem ser reparados, a fim de diminuir as más consequências geradas pelos mesmos.

Dessa forma, sugerimos que, para cada impacto negativo gerado, sejam aplicadas medidas mitigadoras, a fim de reduzi-los e/ou eliminá-los. Sugerimos também, que sejam aplicadas medidas compensatórias, para o caso dos impactos indissociáveis da fase de produção. O investimento de capital, proveniente do empreendedor, para ações sociais e de infraestrutura, voltadas à população, por exemplo, pode ser considerada uma medida compensatória.

Considerando o exposto, inferimos que a aplicação de um sistema de gestão ambiental eficiente é capaz de evitar a geração de alguns aspectos ambientais causadores de impactos, e as boas práticas de produção podem evitar más atitudes, como o despejo de efluentes industriais contendo resíduos de óleo, sem tratamento, diretamente no mar, por exemplo.

Assim, a produção de petróleo, atividade essencial nos dias atuais, e de eminente devastação ambiental, será capaz de atenuar a gravidade dos impactos ambientais gerados e, até mesmo, evitar alguns deles. Dessa forma, o desenvolvimento de tal atividade agredirá menos o meio ambiente e, consequentemente, os elementos que compõem os meios físico, biológico e socioeconômico.

\section{REFERÊNCIAS}

1. ARCADIS tetraplan. Estudo sobre o potencial de geração de energia a partir de resíduos de saneamento (lixo, esgoto), visando incrementar o uso de biogás como fonte alternativa de energia renovável. Disponível em: <http://www.higieneocupacional.com.br/download/radia cao-astete.pdf>. Acesso em: 28 nov. 2012.

2. ASSOCIAÇÃO BRASILEIRA DE NORMAS TÉCNICAS - ABNT. Sistema de gestão ambiental: especificação e diretrizes para so - NBR ISO 14001. Out./ 2004.

3. BAHIA. G. O. IPEA. Cenário mundial influencia matriz energética brasileira. Disponível em: <http://www.ebah.com.br/>. Acesso em: 07 dez. 2012.

4. BARBIERI, J. C. Impacto ambiental. In: Gestão ambiental empresarial: conceitos, modelos e instrumentos. 2. ed. São Paulo: Saraiva, 2007. P. 289-290

5. BRASIL. CONSELHO NACIONAL DO MEIO AMBIENTE - CONAMA. Resolução 001/1986. Brasília, 1986.

$6 . \quad$. Instituto Brasileiro do Meio Ambiente e dos Recursos Naturais Renováveis. Relatório de impacto ambiental - RIMA: atividade de perfuração marítima blocos BM-POT-16 e BMPOT-17 Bacia Potiguar. Brasil, 2010. 41 p.

7. __ Instituto Brasileiro do Meio Ambiente e dos Recursos Naturais Renováveis. Estudo de impacto ambiental - EIA: desenvolvimento e escoamento da produção de petróleo bloco BMC-41, Bacia de Campos. Brasil, 2011. 43 p.

8. . Instituto Brasileiro do Meio Ambiente e dos Recursos Naturais Renováveis. Relatório de impacto ambiental - RIMA: desenvolvimento integrado da produção e escoamento na área denominada Parque das Baleias e no campo de Catuá. Brasil, 2007. 79 p.

9. BOZELLI, R. L.; LOPES, A. F.; SANTOS, L. F.; SILVA, J. M. C. Impactos ambientais da exploração e 
produção de petróleo na bacia de campos, RJ. Brasília, IV Encontro Nacional da Anppas, 2008. Disponível em: < http://www.projetopolen.com.br/materiais/artigos/Impactos\%20Ambien tais\%20da\%20Exploracao\%20e\%20Producao\%20de\%20Petroleo\%20na\%20Bacia\%20de\%20C ampos,\%20RJ..pdf>. Acesso em: 10 set. 2012.

10. CARTA VERDE. Ecod: Carta Capital, 14 jun. 2012. Disponível em: <http://www.cartacapital. com.br/carta-verde/fontes-renovaveis-respondem-por-888-da-matriz-energetica-brasileiradiz-estudo/>. Acesso em: 07 dez. 2012.

11. CORRÊA, O. L. S. Petróleo: noções sobre exploração, perfuração, produção e microbiologia. Rio de Janeiro: ed. Interciência, 2003.

12. DIAS, S. Tipos de processos de refino de petróleo. 2010. Disponível em: <unipeg1.blogs pot.com.br/2010/08/tipos-de-processos-de-refino-de.html>. Acesso em: 07 dez. 2012.

13. DRUMMOND, A. A. R. Perfilagem. Rio de Janeiro: Universidade Federal do Rio de Janeiro. Disponível em: <www.slideshare.net/sydman/introduo-perfilagem-de-poos-5043021>. Acesso em: 07 dez. 2012.

14. EMPRESA DE PESQUISA ENERGÉTICA. Balanço energético nacional 2012 - ano base 2011: Resultados. Disponível em: <https://ben.epe.gov.br/downloads/Resultados_Pre_BEN_2012 .pdf>. Acesso em: 07 dez. 2012.

15. IBGE. Extração, importação, exportação e consumo aparente de petróleo bruto - 1935-87. Disponível em: <http://www.ibge.gov.br/seculoxx/economia/atividade_economica/setoriais/ energia/9_05a_energia1935_93.xls>. Acesso em: 15 nov. 2012.

16. KIMURA, R. M. Indústria brasileira de petróleo: uma análise da cadeia de valor agregado. 2005. 103 f. Monografia (Bacharelado em Economia) - Universidade Federal do Rio de Janeiro, Rio de Janeiro, 2012.

17. LUCCHESI, C. F. Petróleo. São Paulo: Dossiê de recursos naturais, 1998. Disponível em: <http://www.scielo.br/scielo.php?script=sci_arttext\&pid=S0103-40141998000200003\&lang =pt>. Acesso em: 05 nov. 2012.

18. MATOS, A. T. Poluição ambiental: impactos no meio físico. Viçosa: UFV, 2010.

19. MILLIOLLI, V. S. Avaliação da potencialidade da utilização de surfactantes na biorremediação de solo contaminado com hidrocarbonetos de petróleo. Rio de Janeiro: UFRJ, 2008.

20. NOGUEIRA, L. A. H. Perspectivas na produção e processamento de petróleo e gás natural no Brasil. Disponível em: <http://www.cgu.unicamp.br/energia2020/Ter\%E7a\%2011\%20Horta \%20Nogueira.ppt>. Acesso em: 07 dez. 2012.

21. PAZ, J. C.; ALCINO, M. Artigo o petróleo. Disponível em: <http://www.ebah.com. br/content/ABAAAA95YAF/artigo-petroleo>. Acesso em: 23 out. 2012.

22. PETROBRAS. Nossa história. Disponível em: <http://www.petrobras.com.br/pt/quemsomos/nossa-historia>. Acesso em: 05 nov. 2012.

23. __ Plano de negócios 2010-2014. Rio de Janeiro, 2010. Disponível em: <www.petrobras.com.br> Acesso em: 07 dez. 2012.

24. ___ Processos de refino. Curitiba, 2002. Disponível em: <www.slideshare.net/tabVlae/a postila-processosderefinopetrobras>. Acesso em: 07 dez. 2012.

25. Pré-sal. Brasília, 2014. Disponível em: <http://www.petrobras.com.br/pt/nossas- 
atividades/areas-de-atuacao/exploracao-e-producao-de-petroleo-e-gas/pre-sal/>. Acesso em 30 mai. 2014.

26. SÁNCHEZ, L. E. Avaliação de impacto ambiental: conceitos e métodos. São Paulo: Oficina de textos, 2006.

27. SANTOS, P. E. S. et al. Métodos de recuperação secundária convencionais. Sergipe: Universidade Tiradentes, 2010. Disponível em: <www.unit.br/Publica/20102/EX_METODOS_DE_RECUPERACAO.pdf>. Acesso em: $07 \mathrm{dez} .2012$.

28. SILVA, V. P.; PEGADO, É. A. C. Licenciamento ambiental on shore: limite e otimização. Natal: IFRN, 2009.

29. SZKLO, A. S. Fundamentos do refino de petróleo. Rio de Janeiro: ed. Interciência, 2005.

30. THOMAS, J. E. et al. Fundamentos de engenharia de petróleo. Rio de Janeiro: ed. Interciência, 2004. 